\title{
Quantification of Nitrogen Impurity and Estimated Orowan Strengthening Through Secondary Ion Mass Spectroscopy in Aluminum Cryomilled for Extended Durations
}

Clara Hofmeister ${ }^{\mathrm{a}}$, Mikhail Klimov ${ }^{\mathrm{a}}$, Tim Delehanty ${ }^{\mathrm{b}}, \mathrm{Kyu}_{\mathrm{Cho}}^{\mathrm{c}}$, and Yongho Sohn ${ }^{\mathrm{a}, \#}$

${ }^{a}$ Advanced Materials Processing and Analysis Center, Department of Materials Science and Engineering, University of Central Florida, Orlando, FL 32816, USA.

${ }^{\mathrm{b}}$ Pittsburgh Materials Technology, Jefferson Hills, PA 15025, USA.

${ }^{\mathrm{c}}$ Weapons and Materials Research Directorate, U.S. Army Research Laboratory, Aberdeen Proving Ground, MD 21005, USA.

${ }^{\#}$ Corresponding Author: Yongho.sohn@ucf.edu, (407)882-1181 


\begin{abstract}
The strength of aluminum alloys and composites processed through powder metallurgy can be improved through the addition of nano-scale dispersoids introduced during the cryomilling process. Quantification of Orowan Strengthening from these dispersoids requires a reliable measurement of the impurity concentration. Secondary ion mass spectrometry (SIMS) was used to quantify the nitrogen impurity concentration using a ${ }^{14} \mathrm{~N}$ ion implanted standard. An analytical approach is devised to determine the nitrogen concentration of an aluminum alloy and composite based on SIMS measurements. Results are compared to the measurements carried out by gas fusion analysis. An increase in nitrogen concentration was observed with an increase in cryomilling time up to 72 hours. The nitrogen concentration varied from $1.64 \pm 0.17$ at.\% $(0.80 \pm$ 0.08 wt.\%) to $19.12 \pm 1.10$ at. $\%(13.17 \pm 0.71 \mathrm{wt} . \%)$ for the $8 \mathrm{hr}$ and $72 \mathrm{hr}$ cryomilled nanocrystalline AA5083, respectively. Assuming that all nitrogen reacts to form dispersoids, the determined nitrogen concentration was used to calculate the volume and weight fractions of dispersoids, which in turn was used to estimate the strengthening contribution via Orowan strengthening. Orowan strengthening was calculated using dispersoids of 3,9 and $15 \mathrm{~nm}$. The range of Orowan strengthening contribution was estimated in MPa to be from $7.69 \pm 0.78$ to 3.03 \pm 0.31 for the $8 \mathrm{hr}$ nanocrystalline AA5083 sample and $154.97 \pm 10.29$ to $61.09 \pm 4.06$ for the 72 hr nanocrystalline AA5083 sample.
\end{abstract}

Keywords: Aluminum Alloy; Cryomilling; Nitrogen; Strengthening; Secondary Ion Mass Spectrometry 


\section{Introduction}

The low density of aluminum has long made it an attractive material in automotive and other applications especially where improved fuel efficiency and high strength-to-weight ratio are desired. Recently, cryomilling in liquid nitrogen has been investigated as an additional processing step in powder metallurgy to enhance the strength-to-weight ratio. For example, cryomilled aluminum and boron carbide $\left(\mathrm{B}_{4} \mathrm{C}\right)$ metal matrix composites have generated scientific and commercial interests after Ye et al. [1] reported exceptional compressive strength ( 1 GPa). Since then, much work has focused on understanding the mechanisms that contribute to the high strength.

Several mechanisms have been proposed to explain the exceptional strength of these composites including Hall-Petch strengthening, strain-hardening, solution hardening, reinforcement strengthening and Orowan strengthening [1-6]. Among them, Orowan strengthening is of particular interest since the strength of the composite may be improved without loss of ductility. The Orowan-Ashby equation relates the increase in strength to the size and fraction of the nanoscale dispersoids and is given by [7]:

$$
=\frac{0.13 G b}{\ln } \frac{d}{2 b}
$$

where $\mathrm{G}$ is the shear modulus, $\mathrm{b}$ is the Burgers vector, $\lambda$ is the interparticle spacing and $\mathrm{d}$ is the diameter of the dispersoids. The shear modulus and Burgers vector for aluminum is $25.9 \mathrm{GPa}$ and $0.286 \mathrm{~nm}$, respectively [1]. The interparticle spacing, $\lambda$, may be determined utilizing the volume fraction, $f^{V}$, and the diameter, $\mathrm{d}$, of the dispersoids [7]: 


$$
=\frac{2(1 \quad y) d}{3 f^{V}}
$$

Orowan strengthening in these composites is believed to be derived from the presence of nanoscale dispersoids formed during cryomilling. Dispersoids observed via transmission electron microscopy and proposed via modeling are $\theta-\mathrm{Al}_{2} \mathrm{O}_{3}, \chi-\mathrm{Al}_{2} \mathrm{O}_{3}, \mathrm{Al}_{4} \mathrm{C}_{3}$ (hexagonal, hR7), $\mathrm{AlN}$ (hexagonal, hP4 or cubic, cF8), and nitrogen-rich amorphous regions [2, 8-13]. Oxide dispersoids form by the breakup of the native oxide on the aluminum powder [10, 14]. The carbides can form from mechanical alloying of the aluminum powder and the carbon-rich process control agent [10]. Nitrides form due to the interaction of the aluminum powder with the liquid nitrogen during milling.

According to the aluminum-nitrogen equilibrium phase diagram, there is negligible solubility of nitrogen in aluminum [15], therefore it is not unreasonable to assume that all of the nitrogen incorporated is in the form of either a crystalline aluminum nitride (AlN) or an amorphous domain rich in nitrogen. In previous studies it was found that nitrogen concentration increases with milling time up to 26 hours $[9,13]$. If nitrogen resides in the aluminum powders as several nanometer-sized dispersoids of crystalline and/or amorphous phases, an increase in milling time would increase the volume fraction of nanoscale dispersoids, and consequently contribute to the Orowan strengthening. In this study, an analytical approach was devised, utilizing secondary ion mass spectrometry (SIMS), to determine the atomic and weight percent of nitrogen in cryomilled aluminum with an assumption that nitrogen resides in AlN or an amorphous domain of equivalent density. This approach was applied to determine nitrogen concentration from 8 to 72 hours cryomilling time using data from previous work with the aluminum and boron carbide $\left(\mathrm{B}_{4} \mathrm{C}\right)$ composites [13] and current work utilizing $100 \%$ cryomilled 
nanocrystalline aluminum. The Orowan strengthening contribution was then estimated as a function of cryomilling time.

\section{Analytical Approach}

2.1 Secondary ion mass spectroscopy and the relative sensitivity factor

Previously, impurity concentrations of oxygen, hydrogen, carbon and nitrogen were determined through either a gas fusion (GF) or combustion-type techniques [9, 16-18]. The disadvantage of these techniques is that it is not possible to differentiate surface contamination from the bulk impurity concentrations and the sample is consumed during the process. An alternative method of impurity concentration measurement is SIMS which can quantify any element and perform separate analyses of both the surface and the bulk via depth-profiling. In addition, SIMS quantification is more statistically confident than GF chemical analysis.

SIMS measures the quantity of secondary ions produced during sample erosion by the primary ion beam. These counts are dependent on operating parameters such as current, type of primary beam, and material [19]. A relative sensitivity factor (RSF) is calculated in order to convert secondary ion intensity ( counts $\cdot \mathrm{s}^{-1}$ ) from SIMS to atomic density (atoms $\cdot \mathrm{cm}^{-3}$ ) utilizing an ion-implanted calibration sample with a known fluence. An RSF is defined by [20]:

$$
N_{i}=\frac{I_{i}}{I_{m}} R S F
$$

where $\mathrm{N}_{\mathrm{i}}$ is the impurity atomic density $\left(\right.$ atoms $\cdot \mathrm{cm}^{-3}$ ), $\mathrm{I}_{\mathrm{i}}$ is the impurity isotope secondary ion intensity (counts $\cdot \mathrm{s}^{-1}$ ), and $\mathrm{I}_{\mathrm{m}}$ is the matrix isotope secondary ion intensity (counts $\cdot \mathrm{s}^{-1}$ ). An RSF 
can be determined from an ion-implanted calibration sample (assuming constant impurity background) utilizing the relation [20]:

$$
R S F=\frac{I_{m}}{\left[\sum I_{i}\right] I_{b} d}
$$

where, $\varphi$ is the ion implant fluence $\left(\right.$ atoms $\left.\cdot \mathrm{cm}^{-2}\right), \mathrm{d}$ is the implantation depth $(\mathrm{cm}), \Sigma \mathrm{I}_{\mathrm{i}}$ is sum of the impurity isotope secondary ion counts over the depth profile (counts $\cdot \mathrm{cm} \cdot \mathrm{s}^{-1}$ ) and $\mathrm{I}_{\mathrm{b}}$ is background ion intensity of the impurity isotope $\left(\operatorname{counts} \cdot \mathrm{s}^{-1}\right)$. Utilizing a SIMS depth profile of an ion implanted sample and equation (4), the RSF may be determined. Once the RSF is known, equation (3) may be applied to determine the nitrogen concentration in terms of atomic density (number of atoms per unit of volume) for samples with a similar matrix.

In order to convert nitrogen atomic density into atomic and weight percent, it is important to understand in which phase the nitrogen resides. For the composites, it has been shown that $\mathrm{B}_{4} \mathrm{C}$ and nitrogen do not interact during or after the cryomilling process and that nitrogen is found in nitrogen-rich dispersoids within the aluminum grain or in the aluminum grain boundaries [13]. In order to simplify the derivation, it is assumed that all of the atoms of nitrogen are in the crystal structure of aluminum nitride (AlN) or in an amorphous structure of similar density. The atomic density of nitrogen, $N_{N}$, was measured using SIMS. In order to calculate the atomic percent of nitrogen, it is necessary to calculate the atomic density of the various phases present in the composite. The atomic density, $N_{i}$, of element or compound i may be calculated by: 


$$
N_{i}=\frac{{ }_{i} N_{A}}{M_{i}}=\frac{n_{i}}{V_{\text {cell }, i}}
$$

where, $\rho_{m}$ is the density of element or compound $\mathrm{i}, \mathrm{N}_{\mathrm{A}}$ is Avogadro's number, and $\mathrm{M}_{\mathrm{i}}$ is the atomic mass of element or compound i. Alternatively, the atomic density may also be expressed in terms of the number of atoms in its unit cell, $\mathrm{n}_{\mathrm{i}}$, and the volume of the unit cell, $\mathrm{V}_{\text {cell, } \mathrm{i}}$. Calculating the atomic densities of all phases present will be necessary in order to calculate the atomic and weight percent of nitrogen in the composite.

\subsection{Determination of nitrogen concentrations}

The atomic percent of nitrogen is simply the ratio of the nitrogen atomic density, $N_{N}$, to the atomic density of the whole, $N_{T}$, multiplied by 100. $N_{T}$ may be calculated as the atomic density multiplied by the volume fraction of each phase present. The atomic densities of aluminum, $\mathrm{B}_{4} \mathrm{C}$ and $\mathrm{AlN}$ may be calculated from equation (5) or found in tables such as in Burenkov et al. [21]. If, $N_{A l}$ is the atomic density of aluminum, $N_{B_{4} C}$ is the atomic density of $\mathrm{B}_{4} \mathrm{C}, f_{B_{4} C}^{V}$, and $f_{A l N}^{V}$, are the volume fractions of $\mathrm{B}_{4} \mathrm{C}$ and $\mathrm{AlN}$ in the composite, respectively. The atomic percent of nitrogen is expressed as:

$$
\text { at. } \% N=\frac{N_{N}}{N_{A l}\left(1 \quad f_{B_{4} C}^{V} \quad f_{A l N}^{V}\right)+N_{B_{4} C} \times f_{B_{4} C}^{V}+N_{A I N} \times f_{A l N}^{V}} \times 100 \%
$$

A similar derivation may be performed to determine the weight percent of nitrogen in the composite. To determine the weight fraction of nitrogen, it is necessary to calculate the mass 
density of nitrogen atoms, $\mathrm{W}_{\mathrm{N}}$, in the volume, $\mathrm{V} . \mathrm{W}_{\mathrm{N}}$ can be described as the product of the nitrogen atomic density, $N_{N}$, by the molecular weight of nitrogen, $\mathrm{M}_{\mathrm{N}}$, divided by Avogadro's number. The mass density of the composite after cryomilling can be described as the summation of the densities of each component, multiplied by their respective volume fraction. If $\rho_{B_{4} C}, \rho_{A I N}$, and $\rho_{A l}$ are the densities of the $\mathrm{B}_{4} \mathrm{C}$, the $\mathrm{AlN}$ and the $\mathrm{Al}$ phases, respectively, the weight percent of nitrogen may be found by dividing mass density of nitrogen atoms by the composite mass density:

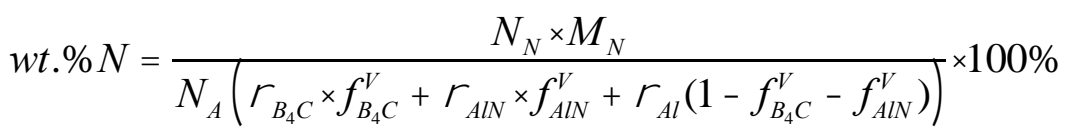

\subsection{Determination of volume fractions}

In order to determine the $\mathrm{B}_{4} \mathrm{C}$ volume fraction, $f_{B_{4} C}^{V}$, it is necessary to 1) assume that grain size does not significantly affect density and 2) assume that the increase in volume due to the formation of $\mathrm{AlN}$ is negligible. Therefore, the volume fraction of $\mathrm{B}_{4} \mathrm{C}$ is the same before and after cryomilling. Before cryomilling, the mass density of $\mathrm{B}_{4} \mathrm{C}$ in the composite is the density of $\mathrm{B}_{4} \mathrm{C}, \rho_{B_{4} C}$, multiplied by the volume fraction of $\mathrm{B}_{4} \mathrm{C}, f_{B_{4} C}^{V}$. The mass density of the composite before cryomilling is given by the sum of the mass densities of $\mathrm{B}_{4} \mathrm{C}$ and $\mathrm{Al}$ multiplied by their respective volume fractions. The weight fraction of $\mathrm{B}_{4} \mathrm{C}, w_{B_{4} C}$ is simply the mass density of $\mathrm{B}_{4} \mathrm{C}$ divided by the mass density of the composite. The volume fraction of $\mathrm{B}_{4} \mathrm{C}$ is related to the weight fraction by: 


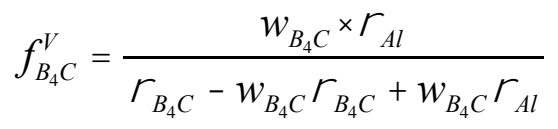

The volume fraction of $\mathrm{B}_{4} \mathrm{C}$ is only dependent on the weight percent of $\mathrm{B}_{4} \mathrm{C}$ added before the cryomilling run. In the case of the $100 \%$ nanocrystalline aluminum, $w_{B_{4} C}=0$ and $f_{B_{4} C}^{V}=0$.

The atomic density of AlN in the composite may be described by the atomic density of pure AlN multiplied by the volume fraction of AlN, $f_{A l N}^{V}$. By stoichiometry, the total number of atoms of nitrogen is equal to half of the total number of atoms of AlN. Therefore, the volume fraction of AlN, $f_{\text {AlN }}^{V}$, is expressed by:

$$
f_{A l N}^{V}=\frac{2 \cdot N_{N}}{N_{A l N}}
$$

The volume fraction of AlN, $f_{A I N}^{V}$, is only a function of the nitrogen atomic density. The atomic and weight percent may be calculated from equations (6) and (7), respectively, since the volume fractions of $\mathrm{B}_{4} \mathrm{C}$ and $\mathrm{AlN}$ can be determined utilizing equations (8) and (9), respectively.

\section{Experimental Details}

The composites with $\mathrm{B}_{4} \mathrm{C}$ reinforcement were produced by cryomilling -325 mesh AA5083 (Valimet Inc) powder with $\mathrm{B}_{4} \mathrm{C}$ particles (ESK Ceramics) at a weight ratio of 4:1 in liquid nitrogen for 8, 12, 16 and 24 hours milling time. Additional gas-atomized AA5083 powder with larger grains $(2 \sim 5 \mu \mathrm{m})$ was added for ductility, and V-blended for up to 24 hours to ensure a homogenous distribution. The AA5083 metal matrix composite (MMC) consisted of $30 \mathrm{wt} . \%$ 
coarse-grained AA5083, 14 wt.\% B 4 C and 56 wt.\% cryomilled-nanocrystalline AA5083. Additional details on the manufacturing process and microstructural constituents of these composites have been reported previously [13]. The composite was polished down to $1 \mu \mathrm{m}$ for chemical analysis by SIMS.

To produce the AA5083 consisting entirely of consolidated nanocrystalline aluminum powders, AA5083 powder was cryomilled utilizing a modified 1S Szegvari attritor in liquid nitrogen operating at $188 \mathrm{rpm}$. Stainless steel milling balls (3/16”) were used with a ball-topowder weight ratio of 32:1. To mitigate agglomeration of the powders, $0.126 \mathrm{wt} . \%$ graphite was added to the attritor as a process control agent. Powders were cryomilled for 24, 48, 60, 67 and 72 hours. After cryomilling, the powder and liquid nitrogen slurry was transferred to a glove box to allow the residual liquid nitrogen to boil off. Cryomilled powders were then sieved ( -325 mesh) to remove any excessively large agglomerates. Chemical analysis of the 24, 48, 60 and 67 hr cryomilled powders were also carried out by GF analysis. The 60 and $72 \mathrm{hr}$ cryomilled powders were cold pressed in air to form compacts and polished down to $1 \mu \mathrm{m}$ for SIMS analysis.

The PHI Adept 1010 Dynamic SIMS System was used to determine the RSF of nitrogen and for depth profiling the cold-pressed nanocrystalline aluminum compact. The PHI Adept utilized Cs ions in positive secondary mode at $90 \mathrm{nA}$, and analyzed the following ion clusters: ${ }^{133} \mathrm{Cs}+{ }^{27} \mathrm{Al},{ }^{133} \mathrm{Cs}+{ }^{24} \mathrm{Mg},{ }^{133} \mathrm{Cs}+{ }^{55} \mathrm{Mn},{ }^{133} \mathrm{Cs}+{ }^{14} \mathrm{~N},{ }^{133} \mathrm{Cs}+{ }^{12} \mathrm{C},{ }^{133} \mathrm{Cs}+{ }^{16} \mathrm{O}$ and ${ }^{133} \mathrm{Cs}+{ }^{11} \mathrm{~B}$. The ${ }^{133} \mathrm{Cs}+{ }^{27} \mathrm{Al}$ signal was used as the matrix signal for quantification. A Cameca IMS3F SIMS, measuring ${ }^{14} \mathrm{~N}$ ions, was utilized in the previous study [13]. The nitrogen concentration was measured for the composite reinforced with $\mathrm{B}_{4} \mathrm{C}$ and cryomilled for 24 hours on both the Cameca and the PHI Adept SIIMS. The ratio of these two counts was used as a conversion factor 
between the two instruments. This conversion factor was used to quantify the SIMS ion counts from the composite with $\mathrm{B}_{4} \mathrm{C}$ reinforcement from the previous study [13] into equivalent ${ }^{133} \mathrm{Cs}+{ }^{14} \mathrm{~N} /{ }^{133} \mathrm{Cs}+{ }^{27} \mathrm{Al}$ ratios which could then be quantified into atomic and weight percent using the RSF.

A $400 \mathrm{kV}$ ion implanter (National Electrostatic Corporation) operating at $232 \mathrm{kV}$ was employed to produce the nitrogen implanted AA5083 standard. Mass separation was used to ensure that the ion implanted species was ${ }^{14} \mathrm{~N}$ and the sample surface was scanned at a $7{ }^{\circ}$ tilt. The implantation fluence was $2.12 \cdot 10^{16}$ atoms $\cdot \mathrm{cm}^{-2}$. The RSF determined for the ${ }^{133} \mathrm{Cs}+{ }^{14} \mathrm{~N}$ ion cluster in AA5083 was $8.68 \cdot 10^{24}$ atoms $\cdot \mathrm{cm}^{-3}$ according to equation 4 . A similar standard was produced by ion implanting an AA5083 composite with $\mathrm{B}_{4} \mathrm{C}$ however, it was not possible to determine an accurate RSF from the ion-implanted composite sample due to its high inherent nitrogen concentration, which obscures the ion-implanted intensity. Therefore, the AA5083 ionimplanted standard was used to quantify nitrogen concentration for both AA5083 composites with $\mathrm{B}_{4} \mathrm{C}$ reinforcement and cold-pressed nanocrystalline AA5083 compacts. All samples, including AA5083 composites with $\mathrm{B}_{4} \mathrm{C}$ reinforcement and cold-pressed nanocrystalline AA5083 compacts examined in this study are listed in Table I.

\section{Results}

A representative SIMS depth profile from a $\mathrm{B}_{4} \mathrm{C}$ reinforced composite produced with 24 hr cryomilled 5083 powders is presented in Figure 1. The depth was calculated based on the total time of acquisition and the sputtering rate determined from the AA5083 N-implanted standard. Several matrix signals are plotted $\left({ }^{133} \mathrm{Cs}+{ }^{27} \mathrm{Al},{ }^{133} \mathrm{Cs}+{ }^{24} \mathrm{Mg}\right.$ and $\left.{ }^{133} \mathrm{Cs}+{ }^{55} \mathrm{Mn}\right)$ as well as the reinforcement chemistry $\left({ }^{133} \mathrm{Cs}+{ }^{11} \mathrm{~B}\right.$ and $\left.{ }^{133} \mathrm{Cs}+{ }^{12} \mathrm{C}\right)$ and common impurity elements $\left({ }^{133} \mathrm{Cs}+\right.$ 
${ }^{14} \mathrm{~N}$ and $\left.{ }^{133} \mathrm{Cs}+{ }^{16} \mathrm{O}\right)$. Because SIMS has different elemental sensitivities, even the relative concentration of each element cannot be directly compared based on count rate. However, all of the signals level off beyond the surface layer $(\sim 250 \mathrm{~nm})$ and suggest that the composite has a uniform bulk composition.

Depth profiles such as that presented in Figure 1 were quantified by normalizing the

${ }^{133} \mathrm{Cs}+{ }^{14} \mathrm{~N}$ impurity signal to the ${ }^{133} \mathrm{Cs}+{ }^{27} \mathrm{Al}$ matrix signal, taking an average of the bulk (beyond the surface layer) concentration and multiplying by the RSF. The nitrogen concentration, for example, for the $24 \mathrm{hr}$ composite was calculated as $3.15 \pm 0.21$ at. $\%$ or $1.59 \pm 0.11 \mathrm{wt} . \%$. Nitrogen concentration was measured for the AA5083 composites with $\mathrm{B}_{4} \mathrm{C}$ reinforcement and the cold-pressed nanocrystalline AA5083. The nitrogen concentrations are reported in Table I.

The wt.\% $\mathrm{N}$ for equivalent cold-pressed nanocrystalline AA5083 compact samples were estimated utilizing the data from the composites reinforced with $\mathrm{B}_{4} \mathrm{C}$ for the shorter cryomilling times $(8,12,16,24 \mathrm{hr})$ as:

$$
\frac{w t . \% N}{56 w t . \% n A l}=\frac{\text { Estimated } w t . \% N}{100 w t . \% n A l}
$$

This approach was applied to data reported in the previous study [13] for composites of various cryomilling times $(8,12,16$, and 24 hours) and are presented by the dashes in Figure 2 . The nitrogen concentrations for longer milling times (60 and 72 hours) were also quantified via SIMS. These samples are cold-pressed nanocrystalline AA5083 compact so the weight fraction of $\mathrm{B}_{4} \mathrm{C}$ in equation 8 was set to zero. The SIMS-quantified nitrogen concentration for the pressed compacts are presented by open squares in Figure 2. For comparison and validation, the nitrogen quantification, via GF, was conducted on samples cryomilled for $24,48,60$, and 67 hours. They 
are presented by open triangles in Figure 2. There is an overall good agreement between the nitrogen concentration determined by SIMS via the analytical approach presented, and that measured by GF, albeit with less deviation in the SIMS approach. Since nitrogen is not known to enrich on the surface of aluminum it is reasonable that the SIMS data corresponds well to that measured by GF analysis.

It is assumed that a linear relationship exists between the nitrogen concentration and the secondary ion counts from SIMS. Standards are typically considered reliable at concentrations up to a few percent of absolute solute concentration. At higher concentrations the linearity of the relationship between the secondary ion counts and the concentration of the solute becomes questionable due to matrix differences. However, in this work quantification by gas fusion aligns very well with the quantification by SIMS for higher solute concentrations and gives an indirect confirmation of linearity.

The results of this study confirm the previous finding that nitrogen concentration increases with cryomilling time up to 26 hours [9, 13], and further document the increase up to 72 hours. The increase shows no indication of saturation even though nitrogen has negligible solubility in aluminum according to the aluminum-nitrogen equilibrium phase diagram [15].

\section{Estimation of Orowan Strengthening Contribution}

Figure 3 presents the estimated increase in strength due to Orowan strengthening, based on equation 1, using the nitrogen concentration determined in this study. The diameter of the dispersoids were varied from 3, 9 and $15 \mathrm{~nm}$ based on microscopic observations reported by Yao et. al [2]. All three dispersoid sizes provide similar increases in strengthening at the shorter cryomilling times, corresponding to a small volume fraction of dispersoids. The strengthening 
contribution at the cryomilling time of 8 hours ranged from $3.03 \pm 0.31$ to $7.69 \pm 0.78 \mathrm{MPa}$, and 24 hours from $10.94 \pm 0.77$ to $27.76 \pm 1.95 \mathrm{MPa}$ for dispersoids of $3-15 \mathrm{~nm}$. The maximum strengthening contribution after 72 hours of cryomilling was estimated to be from $61.09 \pm 4.06$ to $154.97 \pm 10.29 \mathrm{MPa}$. The estimated Orowan strengthening contribution for both the actual and equivalent cold-pressed nanocrystalline AA5083 compacts are reported in Table I. An important assumption made in this study is that the dispersoid size remains between $3-15 \mathrm{~nm}$ in diameter regardless of milling time. Formation of larger dispersoids would reduce the Orowan strengthening contribution.

In this study, the primary method for controlling the nitrogen concentration has been through varying the cryomilling time. Other processing variables such as ball-to-powder ratio, attritor rpm and choice of process control agent may also play a role in nitrogen incorporation. It is believed that nitrogen incorporation is through the trapping and subsequent mechanical alloying of nitrogen with the aluminum agglomerates through the collision of the milling balls [13]. Therefore, since the ball-to-powder ratio and attritor rpm affect the ball collision frequency and speed, these should also affect the rate of nitrogen absorption into the powder. Modification of the surface chemistry of the powders through use of a process control agent may help to increase or decrease the rate of nitrogen mechanical alloying into the powders.

\section{Conclusions}

In order to estimate the nitrogen concentration and distribution, a method to determine the concentration of nitrogen in aluminum MMCs from SIMS was developed. Nitrogen concentration of cryomilled aluminum increased with cryomilling time from 8 to 72 hours. Nitrogen concentration determined by SIMS corresponded well to that derived from gas fusion 
chemical analysis. Previously Orowan strengthening was typically calculated based on dispersoid volume fractions estimated from limited transmission electron microscopy. In this

study, volume fractions were calculated based on nitrogen concentrations measured by SIMS and gas fusion chemical analysis and dispersoids imaged via transmission electron microscopy. The impurity concentrations combined with the size of the dispersoids were used to calculate the Orowan strengthening contribution to the overall composite strength. The Orowan strengthening contribution varied from $7.69 \pm 0.78$ to $3.03 \pm 0.31 \mathrm{MPa}$ for AA5083 cryomilled for 8 hours with dispersoid sizes ranging from 3 to $15 \mathrm{~nm}$. The largest Orowan strengthening contribution came from AA5083 cryomilled for 72 hours which was $154.97 \pm 10.29$ for a $3 \mathrm{~nm}$ dispersoid.

\section{Acknowledgments}

The use of the Materials Characterization Facility is gratefully acknowledged. The ionimplanted standard was graciously provided by Dr. Fabian Naab from the University of Michigan. The content of this paper is part of a thesis submitted by C. Hofmeister to the University of Central Florida in partial fulfillment of the requirements for the M.S. degree in Materials Science and Engineering. This research was sponsored by the U.S. Army Research Laboratory and was accomplished under Cooperative Agreement W911NF-08-2-0026. The views, opinions, and conclusions made in this document are those of the authors and should not be interpreted as representing the official policies, either expressed or implied, of the Army Research Laboratory or the U.S. Government. The U.S. Government is authorized to reproduce and distribute reprints for Government purposes notwithstanding any copyright notation herein.

\section{References}


1. Ye, J., et al., A tri-modal aluminum based composite with super-high strength. Scripta Materialia, 2005. 53(5): p. 481-486.

2. Yao, B., et al., Microstructural features influencing the strength of Trimodal Aluminum Metal-Matrix-Composites. Composites Part A: Applied Science and Manufacturing, 2010. 41(8): p. 933-941.

3. Witkin, D.B. and E.J. Lavernia, Synthesis and mechanical behavior of nanostructured materials via cryomilling. Progress in Materials Science, 2006. 51(1): p. 1-60.

4. Lavernia, E.J., B.Q. Han, and J.M. Schoenung, Cryomilled nanostructured materials: Processing and properties. Materials Science and Engineering: A, 2008. 493(1-2): p. $207-$ 214.

5. Ferguson, J.B., et al., Predicting tensile and compressive mechanical properties of bimodal nano-aluminum alloys. Scripta Materialia, 2014. 72-73: p. 13-16.

6. Joshi, S.P. and K.T. Ramesh, An enriched continuum model for the design of a hierarchical composite. Scripta Materialia, 2007. 57(9): p. 877-880.

7. Dieter, G.E., Strengthening from Fine Particles, in Mechanical Metallurgy, M.B. Bever, et al., Editors. 1976, McGraw-Hill: New York. p. 221-227.

8. Li, Y., et al., HRTEM and EELS study of aluminum nitride in nanostructured Al 5083/B 4 C processed via cryomilling. Acta Materialia, 2010. 58(5): p. 1732-1740.

9. Goujon, C., et al., Mechanical alloying during cryomilling of a 5000 Al alloy/AlN powder: the effect of contamination. Journal of Alloys and Compounds, 2001. 315: p. 276-283.

10. Singer, R.F., W.C. Oliver, and W.D. Nix, Identification of Dispersoid Phases Created in Aluminum During Mechanical Alloying. Metallurgical and Materials Transactions A, 1980. 11A: p. 1895-1901.

11. Disko, M.M., M.J. Luton, and H. Shuman, Energy-loss near-edge fine structure and compositional profiles of cryomilled oxide-dispersion-strengthened aluminum. Ultramicroscopy, 1991. 37: p. 202-209.

12. Susegg, O., et al., HREM study of dispersoids in cryomilled oxide dispersion strengthened materials. Philosophical Magazine A, 1993. 68(2): p. 367-380.

13. Hofmeister, C., et al., Composition and structure of nitrogen-containing dispersoids in trimodal aluminum metal-matrix composites. Journal of Materials Science, 2010. 45: p. 4871-6.

14. Benjamin, J.S. and J. Bomford, Dispersion Strengthened Aluminum Made by Mechanical Alloying. Metallurgical and Materials Transactions A, 1977. 8A: p. 1301-5.

15. Al-N, in Landolt-Bornstein - Group IV Physical Chemistry Numberical Data and Functional Relationships in Science and Technology. SpringerMaterials. p. 173-174.

16. Hashemi-Sadraei, L., et al., Influence of Nitrogen Content on Thermal Stability and Grain Growth Kinetics of Cryomilled Al Nanocomposites. Metallurgical and Materials Transactions A, 2011. 43(2): p. 747-756.

17. Hofmeister, C., et al. Effect of Process Control Agent on the Microstructure and Mechanical Behavior of an Aluminum and $B_{4} C$ Metal Matrix Composite. in TMS (The Minerals, Metals \& Materials Society), 2014. 2014. San Diego, CA: John Wiley \& Sons, Inc.

18. Ye, J., J. He, and J.M. Schoenung, Cryomilling for the Fabrication of a Particulate $B_{4} C$ Reinforced Al Nanocomposite: Part I. Effects of Process Conditions on Structure. Metallurgical and Materials Transactions A, 2006. 37A: p. 3099-3109. 
19. Newbury, D.E., Quantitative Analysis by Secondary Ion Mass Spectrometry, in Quantitative Surface Analysis of Materials, N.S. McIntyre, Editor. 1978, American Society for Testing and Materials. p. 127-149.

20. Wilson, R.G., F.A. Stevie, and C.W. Magee, Quantification, in Secondary Ion Mass Spectrometry: A Practical Handbook for Depth Profiling and Bulk Impurity Analysis. 1989, John Wiley \& Sons: New York. p. 3.1-1-3.1-12.

21. Burenkov, A.F., et al., Tables of Ion Implantation Spatial Distributions. 1986, Amsterdam: Gordon and Breach Science Publishers. 


\section{List of Figures}

Figure 1: Typical SIMS depth profile from an AA5083 composite with $\mathrm{B}_{4} \mathrm{C}$ reinforcement derived via $24 \mathrm{hr}$ cryomilling.

Figure 2: Nitrogen Concentration as a function of cryomilling time from 8 to 72 hours. The "estimated $100 \%$ cryo from 14:30 data", in this work, has been quantified from the SIMS ratios reported by Hofmeister et al. [13].

Figure 3: Estiamted Orowan strengthening contribution as a function of cryomilling time. 

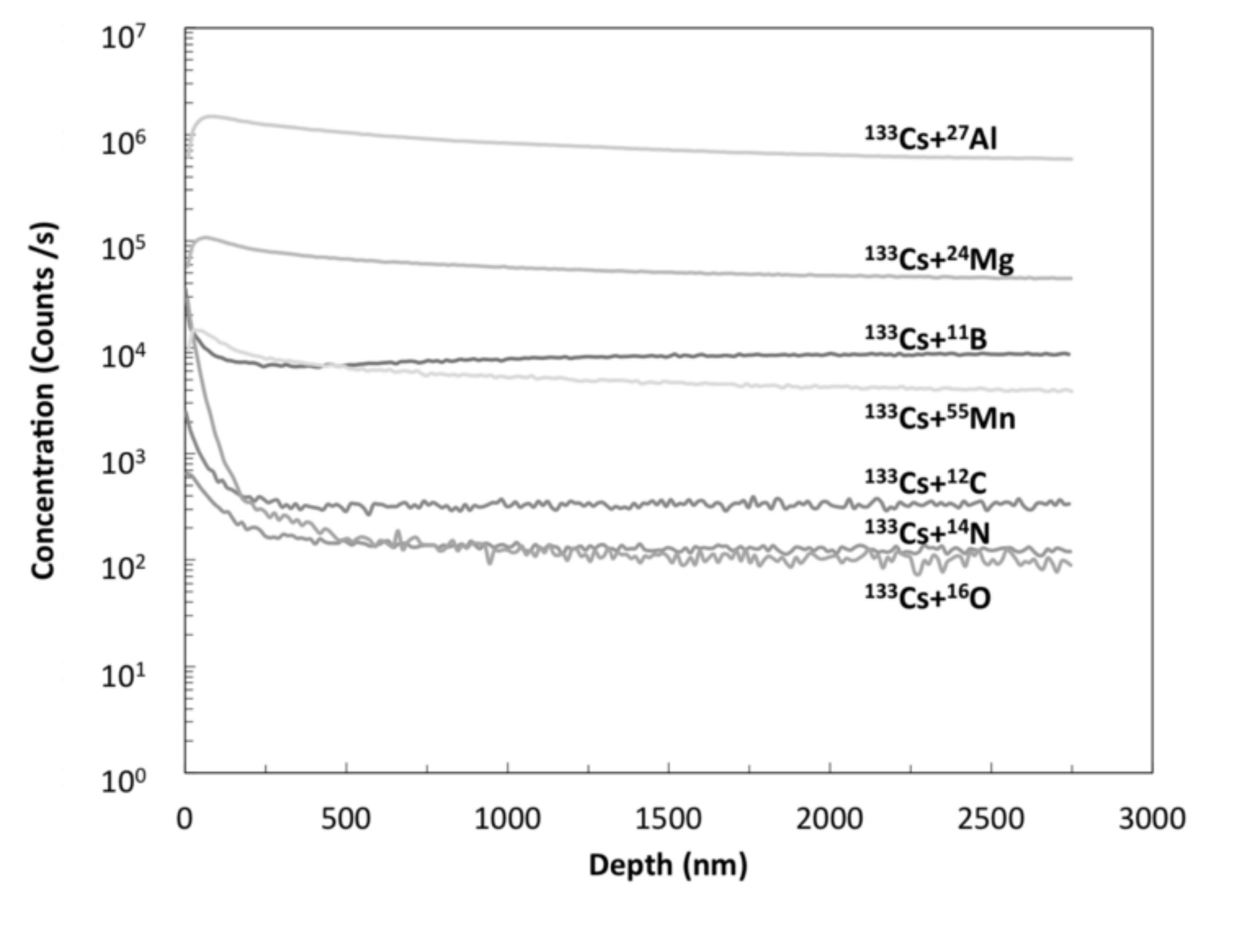

pop
pop 


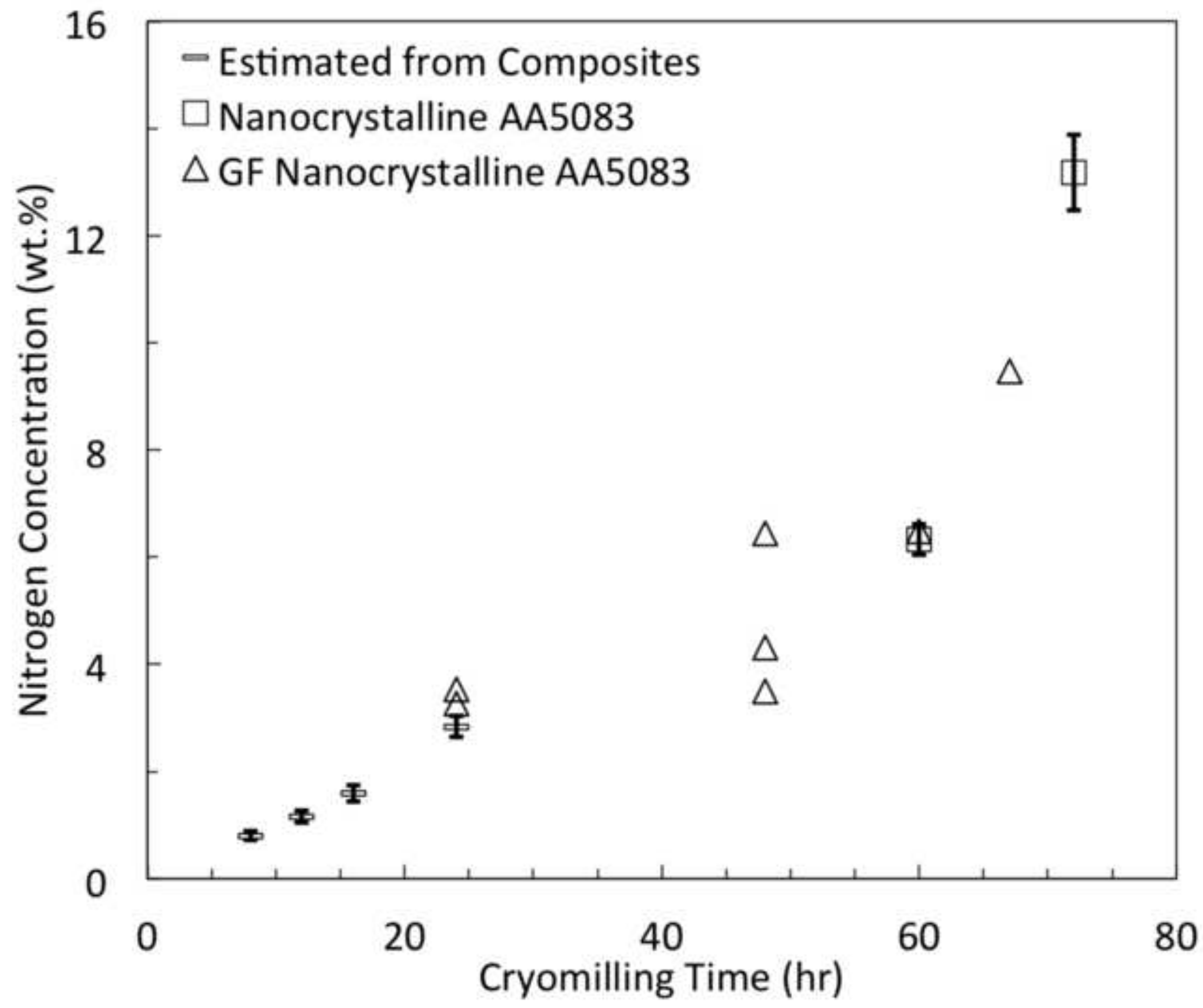




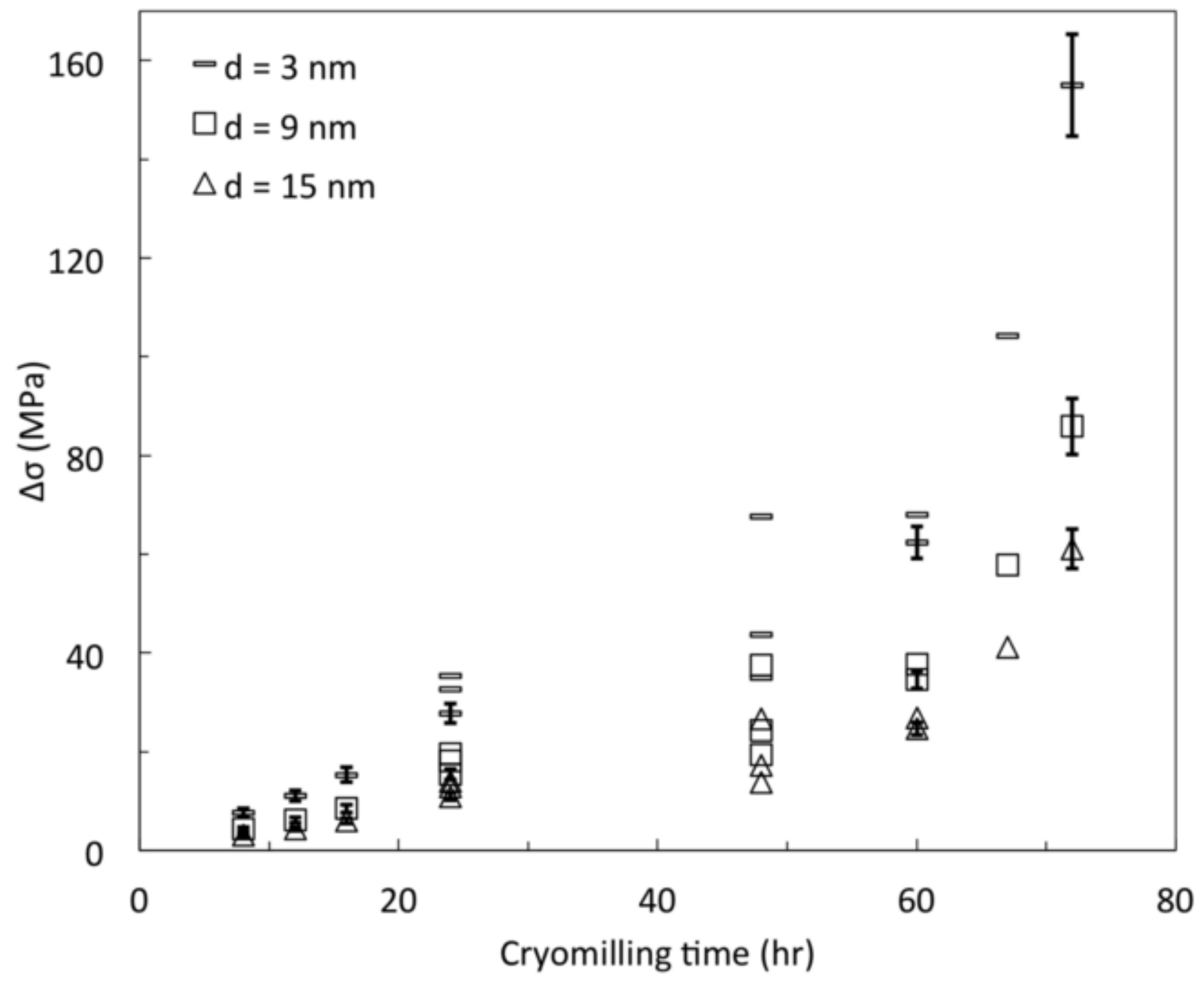


Table I: Summary of nanocrystalline AA5083 and AA5083 composites samples. Measured nitrogen concentrations, estimated AlN volume fractions and Orowan strengthening are reported.

\begin{tabular}{|c|c|c|c|c|c|c|c|}
\hline & \multirow{2}{*}{$\begin{array}{l}\text { Cryomillling } \\
\text { time (hr) }\end{array}$} & \multirow{2}{*}{$\begin{array}{c}\mathrm{B}_{4} \mathrm{C} \text { added } \\
\text { (wt. } \% \text { ) }\end{array}$} & \multicolumn{2}{|c|}{ Nitrogen Concentration } & \multirow{2}{*}{$\begin{array}{l}\text { Volume Fraction } \\
\text { of AlN }\left(10^{-3}\right)\end{array}$} & \multirow{2}{*}{$\mathrm{d}(\mathrm{nm})$} & \multirow{2}{*}{$\Delta \sigma(\mathrm{MPa})$} \\
\hline & & & (at.\%) & (wt.\%) & & & \\
\hline \multicolumn{8}{|c|}{$\mathrm{B}_{4} \mathrm{C}$ Reinforced Composites } \\
\hline $8 \mathrm{hr}+\mathrm{B}_{4} \mathrm{C}$ & 8 & 14 & $0.92 \pm 0.09$ & $0.45 \pm 0.05$ & $5.35 \pm 0.54$ & - & - \\
\hline $12 \mathrm{hr}+\mathrm{B}_{4} \mathrm{C}$ & 12 & 14 & $1.32 \pm 0.13$ & $0.65 \pm 0.06$ & $7.68 \pm 0.74$ & - & - \\
\hline $16 \mathrm{hr}+\mathrm{B}_{4} \mathrm{C}$ & 16 & 14 & $1.80 \pm 0.17$ & $0.89 \pm 0.08$ & $10.54 \pm 0.99$ & - & - \\
\hline $24 \mathrm{hr}+\mathrm{B}_{4} \mathrm{C}$ & 24 & 14 & $3.15 \pm 0.21$ & $1.59 \pm 0.11$ & $18.83 \pm 1.28$ & - & - \\
\hline \multicolumn{8}{|c|}{ Nanocrystalline AA5083 } \\
\hline \multirow{3}{*}{ Calculated $8 \mathrm{hr}$} & \multirow{3}{*}{8} & \multirow{3}{*}{0} & \multirow{3}{*}{$1.64 \pm 0.17$} & \multirow{3}{*}{$0.80 \pm 0.08$} & \multirow{3}{*}{$9.55 \pm 0.96$} & 3 & $7.69 \pm 0.78$ \\
\hline & & & & & & 9 & $4.26 \pm 0.43$ \\
\hline & & & & & & 15 & $3.03 \pm 0.31$ \\
\hline \multirow{3}{*}{ Calculated $12 \mathrm{hr}$} & \multirow{3}{*}{12} & \multirow{3}{*}{0} & \multirow{3}{*}{$2.36 \pm 0.23$} & \multirow{3}{*}{$1.16 \pm 0.11$} & \multirow{3}{*}{$13.71 \pm 1.32$} & 3 & $11.09 \pm 1.09$ \\
\hline & & & & & & 9 & $6.15 \pm 0.60$ \\
\hline & & & & & & 15 & $4.37 \pm 0.43$ \\
\hline \multirow{3}{*}{ Calculated $16 \mathrm{hr}$} & & & & & & 3 & $15.31 \pm 1.46$ \\
\hline & 16 & 0 & $3.21 \pm 0.30$ & $1.59 \pm 0.15$ & $18.83 \pm 1.77$ & 9 & $8.49 \pm 0.81$ \\
\hline & & & & & & 15 & $6.04 \pm 0.58$ \\
\hline & & & & & & 3 & $27.76 \pm 1.95$ \\
\hline Calculated $24 \mathrm{hr}$ & 24 & 0 & $5.63 \pm 0.38$ & $2.84 \pm 0.19$ & $33.62 \pm 2.28$ & 9 & $15.39 \pm 1.08$ \\
\hline & & & & & & 15 & $10.94 \pm 0.77$ \\
\hline & & & & & & 3 & 32.63 \\
\hline GF $24 \mathrm{hr}$ run1 & 24 & 0 & $6.11 *$ & $3.27 *$ & 39.29 & 9 & 18.09 \\
\hline & & & & & & 15 & 12.87 \\
\hline & & & & & & 3 & 35.37 \\
\hline GF $24 \mathrm{hr}$ run2 & 24 & 0 & $6.58^{*}$ & $3.53^{*}$ & 42.45 & 9 & 19.61 \\
\hline & & & & & & 15 & 13.94 \\
\hline & & & & & & 3 & 35.05 \\
\hline GF $48 \mathrm{hr}$ run1 & 48 & 0 & $6.53^{*}$ & $3.50^{*}$ & 42.08 & 9 & 19.43 \\
\hline & & & & & & 15 & 13.82 \\
\hline & & & & & & 3 & 43.71 \\
\hline GF $48 \mathrm{hr}$ run2 & 48 & 0 & $7.98 *$ & $4.31^{*}$ & 51.94 & 9 & 24.23 \\
\hline & & & & & & 15 & 17.23 \\
\hline & & & & & & 3 & 67.67 \\
\hline GF $48 \mathrm{hr}$ run3 & 48 & 0 & $11.72 *$ & $6.45^{*}$ & 78.18 & 9 & 37.51 \\
\hline & & & & & & 15 & 26.68 \\
\hline & & & & & & 3 & 68.02 \\
\hline GF $60 \mathrm{hr}$ & 60 & 0 & $11.78^{*}$ & $6.48^{*}$ & 78.55 & 9 & 37.70 \\
\hline & & & & & & 15 & 26.81 \\
\hline & & & & & & 3 & $62.35 \pm 3.20$ \\
\hline $60 \mathrm{hr}$ & 60 & 0 & $9.97 \pm 0.48$ & $5.99 \pm 0.28$ & $72.48 \pm 3.45$ & 9 & $34.56 \pm 1.77$ \\
\hline & & & & & & 15 & $24.58 \pm 1.26$ \\
\hline & & & & & & 3 & 104.31 \\
\hline GF $67 \mathrm{hr}$ & 67 & 0 & $16.75^{*}$ & $9.46^{*}$ & 115.61 & 9 & 57.82 \\
\hline & & & & & & 15 & 41.12 \\
\hline & & & & & & 3 & $154.97 \pm 10.29$ \\
\hline $72 \mathrm{hr}$ & 72 & 0 & $19.12 \pm 1.10$ & $13.17 \pm 0.71$ & $162.63 \pm 9.04$ & 9 & $85.9 \pm 5.70$ \\
\hline & & & & & & 15 & $61.09 \pm 4.06$ \\
\hline
\end{tabular}

*Measured by gas fusion chemical analysis 


\section{Equation in graphic form}

Equations in proper format:

Eq. 1: $\Delta \sigma=\frac{0.13 G b}{\lambda} \ln \frac{d}{2 b}$

Eq. 2: $\lambda=\frac{2(1-y) d}{3 f^{V}}$

Eq. 3: $N_{i}=\frac{I_{i}}{I_{m}} R S F$

Eq. 4: $R S F=\frac{\phi I_{m}}{\left[\sum I_{i}\right]-I_{b} d}$

Eq. 5: $N_{i}=\frac{\rho_{i} N_{A}}{M_{i}}=\frac{n_{i}}{V_{\text {cell }, i}}$

Eq. 6: $\quad$ at. $\% N=\frac{N_{N}}{N_{A l}\left(1-f_{B_{4} C}^{V}-f_{A I N}^{V}\right)+N_{B_{4} C} \cdot f_{B_{4} C}^{V}+N_{A I N} \cdot f_{A I N}^{V}} \cdot 100 \%$

Eq. 7: $\quad w t . \% N=\frac{N_{N} \cdot M_{N}}{N_{A}\left(\rho_{B_{4} C} \cdot f_{B_{4} C}^{V}+\rho_{A I N} \cdot f_{A I N}^{V}+\rho_{A l}\left(1-f_{B_{4} C}^{V}-f_{A I N}^{V}\right)\right)} \cdot 100 \%$

Eq. 8: $f_{B_{4} C}^{V}=\frac{w_{B_{4} C} \cdot \rho_{A l}}{\rho_{B_{4} C}-w_{B_{4} C} \rho_{B_{4} C}+w_{B_{4} C} \rho_{A l}}$

Eq. 9: $f_{A I N}^{V}=\frac{2 \cdot N_{N}}{N_{A I N}}$

Eq. 10: $\frac{w t . \% N}{56 w t . \% n A l}=\frac{\text { Estimated } w t . \% N}{100 w t . \% n A l}$ 